fassungsgerichts). Inwieweit die Große Koalition überfällige Veränderungen in dieser Hinsicht tatsächlich auf den Weg bringen wird, darauf kann das Buch natürlich noch keine Antwort geben.

Lothar Probst

\title{
Politisches Denken in Deutschland nach 1945: kontextualisierte Auslegung von Texten
}

Greven, Michael Th.: Politisches Denken in Deutschland nach 1945. Erfahrung und Umgang mit der Kontingenz in der unmittelbaren Nachkriegszeit, Verlag Barbara Budrich, Opladen 1 Farmington Hills 2007, 304 Seiten, € 36,-.

Die erstaunliche Fülle des politischen Denkens in der Zeit von 1945 bis September 1949 ist das Thema der eindruckvollen Darstellung von Michael Th. Greven. Der Akzent liegt nicht auf den Zeitschriften, sondern auf den kaum untersuchten selbständigen Publikationen. In fünf thematischen Kapiteln (Politik der geistigen Umkehr und Erziehung, Das Gemeinwesen neu begründen: Varianten des Föderalismus, Gegen Kapitalismus und Kollektivismus: Dritte Wege, Die Sowjetunion als Vorbild, Freiheit im Planstaat) werden Texte von bekannten Autoren wie etwa Friedrich Meinecke, Karl Jaspers, Eugen Kogon und weniger bekannten wie Felix Schottlaender, Hans Peters und Georg Laforet vorgestellt.

Zwei Perspektiven sind leitend: Zum einen, das Markenzeichen von Grevens Publikationen seit Ende der 1990er Jahre, ist es der kontingenztheoretische Ansatz, mit dem gefragt wird, wie offen die Situation nach der vollständigen Kriegsniederlage wahrgenommen wurde. Dass der kommende Kalte Krieg auf erhebliche Weise präsent war und der Atombombeneinsatz dagegen kaum, überrascht. Seltsam berührt, dass nur beim Arzt Rudolf Degkwitz (S. 37) ausdrücklich von jüdischen und russischen Opfern des Nationalsozialismus die Rede ist. Zum anderen stemmt sich das kontextualisierende Vorgehen gegen Lesarten, die von der Position des Nachgeborenen besserwisserisch argumentieren. Beide Perspektiven sind fruchtbar und führen dazu, dass manch ein Urteil revidiert wird. Mehrfach wird das Problem einer Besatzung mit Demokratisierungsabsicht eruiert, das enorme Schwierigkeiten im Verhältnis von Fremd- und Selbstbestimmung in sich birgt (S. 19, S. 25 zum Beispiel).

Greven schreibt keine Geschichte des politischen Denkens. Nicht die ganze Breite interessiert, sondern eine „Symptomatik“ vermittels derer zentrale Fragen diskutiert werden können. Methodisch dominieren hermeneutische Deutungen der Arbeiten von Wissenschaftlern, Schriftstellern, Publizisten und Gelegenheitsautoren. Die Fülle der Einsichten lässt sich nur punktuell andeuten. Eine echte Entdeckung sind die Ideen von Otto Feger, der sich für eine alemannische Demokratie nach Schweizer Vorbild einsetzte. Lesenswerte Darstellungen gibt es zu Alfred Weber, zu Friedrich Meinecke, und mit Blick auf Karl Jaspers sei hervorgehoben, dass dessen Einfluss unmittelbar nach 1945 eine rückwirkende Konstruktion ist, an der Jürgen Habermas wesentlich beteiligt war. Zu den Entdeckungen des Bandes gehört auch Hans Peters, ein tief im Katholischen verankerter Jurist. Seine Bücher thematisieren kulturelle Fragen geistiger Umkehr, er stritt für Föderalismus und für eine wehrhafte Demokratie, die sich von der Weimarer Variante abgrenzt. Insbesondere betonte er die ethischen Grundlagen der Demokratie, und zwar mit Rekurs auf die trefflich charakterisierte US-amerikanische Bewegung für „Moral Re-Armament“ (S. 132 f.). 
Wilhelm Röpke gilt Greven nicht als Ordoliberaler, da seine Kritik am Kollektivismus zugleich eine Kritik am Liberalismus des 19. Jahrhundert enthält. Sein Denken kreist um den freien Menschen in einem autoritativen, aber antizentralistischen Staat. Um den Nöten der Massengesellschaft zu entkommen forderte er eine Politik der Begrenzung von Betriebsgrößen, die den Abbau des Proletariats erlaube (S. 173).

Überzeugend sind die Darstellungen zu Eugen Kogon und den katholisch-sozialistischen Vorstellungen von Walter Dirks. Sie werden von den Darlegungen zum Politikwissenschaftler Richard Löwenthal noch übertroffen, die viel Sinn für die Probleme eines bewussten normativen Pluralismus offenbaren, der nicht nur eine demokratische Selbsteinschränkung, sondern auch sozialistische Inhalte absichern muss. Dass Ernst Niekisch und Helmut Schelsky in einem Block zur Freiheit im Planstaat verhandelt werden, ist an sich schon reizvoll. Insbesondere Schelsky wird sehr differenziert traktiert. Beispielhaft sei die These einer Verbindung zwischen traditioneller Arbeiterbewegung und Schelskys Ordnungsvorstellungen erwähnt.

Das geschichtsspekulative Wegerzählen von Kontingenz wurde im Marxismus-Leninismus mit riesigem Aufwand betrieben. Gerade auf diese Weise konnten die politische Unfreiheit der Bevölkerung, ihre ideologische Mobilisierung und gleichzeitige Passivierung hinsichtlich öffentlichen freien Tuns mit dem faktischen Voluntarismus der Parteikader Hand in Hand gehen. Am „Irrweg einer Nation“ von Alexander Abusch wird dies deutlich. So treffend Greven das Aussparen von Leo Trotzki als exemplarische Geschichtspolitik aufzeigt, bleibt er dem Rezensenten hier zu sehr im Prinzipiellen. Es wäre durchaus interessant, den frühen Goethe-Kult in der sowjetisch besetzten Zone auszuleuchten. Er wird bei Abusch vorgedacht, Walter Ulbricht hat ihn forciert und den Schlussmonolog von Faust in eine sozialistische Vision umgedeutet. Der Ideologe Abusch wäre zudem in den Strang der „MisereTheorie“, also jener Erklärungslinie einzubetten, die schon von Karl Marx und Friedrich Engels begonnen, über Franz Mehring fortgeführt wurde und in der Auseinandersetzung mit dem Nationalsozialismus als eine eigene Variante der Sonderwegstheorie ausgeformt wird. Greven weist zwar auf diesen Umstand hin, widmet dem Um- und Ausbau des Ansatzes aber keine weitere Aufmerksamkeit.

Wenn man die Texte auf sich wirken lässt, kommt die Frage auf, ob die europäische Problematik ein selbständiges Thema abgegeben hätte. Europa und das Ost-West-Thema waren nicht nur Gegenstand von Zeitschriftendebatten. Von Ernst Niekisch hätte in diesem Sinne die ausgesparte 1947er Broschüre „Ost-West“ Beachtung verdient. Dort heißt es programmatisch: „Auch der europäische Bürger hat seinen schwarzen Mann, durch den er sogleich in Harnisch zu bringen ist: der Russe ist dieser schwarze Mann. Im antirussischen Affekt kommt die Geringschätzung, ja Verachtung des Bürgers gegen die feudal-junkerliche und ländlich-bäuerliche Lebensform zum Ausbruch. ... ... Es würde sich lohnen, diesen antirussischen Affekt ebenso zu analysieren wie seine Geschichte zu schreiben." ${ }^{2}$

Greven kontextualisiert und aktualisiert die ausgewählten Texte, dabei ist manch ein Exkurs (zum Beispiel zur Totalitarismustheorie) etwas üppig geraten. Stets wird die verfügbare Forschungsliteratur abwägend herangezogen, wobei der Autor keinen Interpreten ungeschoren lässt. Zu den Stärken des Buches gehört, dass es zugleich theoretische Interpretation, Lesebuch und Schulung der politischen Urteilskraft ist.

Harald Bluhm 